\title{
Analysis of Adverse Events in the Department of Obstetrics and Gynecology, Cipto Mangunkusumo Hospital, in 2015
}

\author{
IPG Kayika ${ }^{1}$, Lucas Christiawan², Atikah Sayogo Putri ${ }^{3}$
}

\begin{abstract}
Background: Medical errors are a serious threat for they can lead to injury and death of the patients, as well as increased healthcare cost. According to the Institute of Medicine 2000 report, there were 3 to $16 \%$ of adverse events (AEs) occurred in inpatient care in United States, Denmark, United Kingdom, and Australia. However, AEs data in Indonesia is still limited. This study aimed to identify the distribution of AEs in the Department of Obstetrics and Gynecology (Ob-gyn) of Cipto Mangunkusumo Hospital based on locations, contributing factors, failure to prevent the occurrence, and additional length of stay.

Materials and methods: Cross-sectional study was conducted towards AEs occurring in the Department of Ob-gyn of Cipto Mangunkusumo Hospital during January to December 2015. Data were obtained from Public Service Coordinator which had been clinically audited with the root cause analysis method.

Results: During 2015, 36 AEs were reported, followed by a clinical audit by clinical risk management team. Twenty-four cases were included in this study. Based on the location, 13 (54\%) cases occurred in the emergency room (ER), 4 (17\%) in intensive care unit (ICU), 4 (17\%) in operation theatre, and $3(12 \%)$ in the hospital ward. Based on the contributing factor, 18 cases $(75 \%)$ were due to lack of knowledge and skill of the medical personnel, $4(17 \%)$ were due to other causes, and $2(33 \%)$ were due to technical error. Based on the failure to prevent the occurrence, there were eight cases (33\%) of delayed medical care or intervention, six $(25 \%)$ of malpractice, five $(21 \%)$ of misdiagnosis, three (13\%) of failure to act based on test results, and two (8\%) of failure to take precautions. The median of additional length of stay was of 2 days ( $0-34$ days; $95 \% \mathrm{Cl}$ ). Conclusion: Most of AEs in Department of Ob-gyn of Cipto Mangunkusumo Hospital, in 2015 occurred in ER (54\%). The most frequent cause was lack of knowledge and skill of the medical personnel (75\%), with delayed medical care or treatment as the most frequent failure to prevent the occurrence (33\%).

Keywords: Adverse events, Public service coordinator, Quality committee of patient safety and performance, Root cause analysis.

Journal of South Asian Federation of Obstetrics and Gynaecology (2021): 10.5005/jp-journals-10006-1862
\end{abstract}

\section{INTRODUCTION}

Adverse events (AEs), defined by the Institute of Medicine (IOM) as an injury due to medical care but not the underlying medical condition is not an uncommon phenomenon. ${ }^{1}$ They are a serious threat to public health for it leads to increased mortality and morbidity rates, as well as healthcare cost. Financial loss in the United States due to AEs can stretch to USD 17-29 billion.' Based on the IOM 2000 report, AEs occurred in 3-16\% of inpatient care in United States, Denmark, United Kingdom, and Australia. ${ }^{2}$ In the field of obstetrics and gynecology, the AEs rate can reach up to $10 \%$ from all cases. As much as $70 \%$ of the AEs were due to miscommunication and lack of cooperation within the team, half of which were indeed preventable., ${ }^{3,4}$ Medical errors are classified as diagnostic, therapeutic, preventive, and others such as miscommunication or failure to provide appropriate medical equipment. ${ }^{5}$

However, data about AEs occurring in Indonesia are limited. According to 2007 provincial report of patient safety incident (KKP-RS 2008), Jakarta was ranked first in the incidence of $37.9 \%$, followed by eight other provinces: West Java (15.9\%), Special Region of Yogyakarta (13.9\%), East Java (11.7\%), Nanggroe Aceh Darussalam (10.7\%), South Sumatra (6.9\%), West Java (2.8\%), Bali (1.4\%), and South Sulawesi $(0.7 \%)^{6}$

Several contributing factors of the occurrence of AEs were environmental factor, organization factor, human resources factor, subject in the incident, drugs factor, equipment, and
1,2,3 Department of Obstetrics and Gynecology, Cipto Mangunkusumo Hospital, Jakarta Pusat, Jakarta, Indonesia

Corresponding Author: Lucas Christiawan, Department of Obstetrics and Gynaecology, Cipto Mangunkusumo Hospital, Jakarta Pusat, Jakarta, Indonesia, Phone: +081316511149, e-mail: Lucasfkuaj@gmail.com

How to cite this article: Kayika IPG, Christiawan L, Putri AS. Analysis of Adverse Events in the Department of Obstetrics and Gynecology, Cipto Mangunkusumo Hospital, in 2015. J South Asian Feder Obst Gynae 2021;13(1):6-10.

Source of support: Nil

Conflict of interest: None

documentation. Most AEs occur in the hospital ward, with violation of regulation being the leading cause of $A E s$ that leads to failure to warn about injury prevention and nosocomial infection. ${ }^{3}$

In Indonesia, the standard of patient safety refers to Hospital Patient Safety Standards issued by the Joint Commission of Accreditation of Health Organization in 2002. A movement for better patient safety was initiated by establishing Hospital Patient Safety Committee (KPPRS) by Indonesian Hospital Association (PERSI) in 2005. Following the committee establishment, a national guideline and regulation of patient safety were issued by the government.

( ) Jaypee Brothers Medical Publishers. 2021 Open Access This article is distributed under the terms of the Creative Commons Attribution 4.0 International License (https://creativecommons.org/licenses/by-nc/4.0/), which permits unrestricted use, distribution, and non-commercial reproduction in any medium, provided you give appropriate credit to the original author(s) and the source, provide a link to the Creative Commons license, and indicate if changes were made. The Creative Commons Public Domain Dedication waiver (http://creativecommons.org/publicdomain/zero/1.0/) applies to the data made available in this article, unless otherwise stated. 
In Cipto Mangunkusumo Hospital (RSCM), our hospital serving as a national referral and teaching hospital, established quality committee to perform the clinical audit in 2016, initiating an electronic-based incident data, rendering a better systematic database. Identifying AEs occurring in 2015 as the database was challenging as it was not as systematic. This study aimed for identifying the distribution of AEs occurring in the Department of Obstetrics and Gynecology (Ob-gyn) of Cipto Mangunkusumo Hospital, in 2015, based on location, contributing factor, event occurred, and additional length of stay.

\section{Materials and Methods}

We conducted a cross-sectional study, which was an analytic descriptive study of AEs in the Department of Ob-gyn of RSCM from January to December 2015. Samples were obtained from all AEs incidence report in Ob-gyn Department of RSCM during the research period that fulfilled inclusive criteria, which was incident report that had been audited by the clinical risk management team of Ob-gyn Department of RSCM and was classified as AE. Incomplete $A E$ reports were excluded from the study. The distribution of AEs was classified based on the location it occurred, the contributing factor, and the failure to prevent the occurrence. Additional length of stay following the occurrence of $A E$ was also presented in mean and standard deviation if the data were normally distributed, or in median and range if it was abnormally distributed (Flowchart 1).

This study was approved by the Ethic Committee of the Faculty of Medicine of Universitas Indonesia (0717/UN2.F1/ETIK/2018). The data used in this study were obtained from audit results from the clinical risk management team of Ob-gyn Department of RSCM. The authors did not have direct contact with the patients and guaranteed the confidentiality of the audit data used in this study.

\section{Results}

There were 36 cases reported as AEs to Public Service Division of RSCM Ob-gyn Department from January to December 2016. All data had been analyzed using the root cause analysis method by the clinical risk management team. Twelve cases did not fulfill inclusive criteria, therefore, were excluded from the study. Five cases were declared not AEs by the clinical risk management team. The other seven were excluded due to event occurrence in 2014 (four cases), two cases did not have complete data, and one case occurred outside RSCM. Flowchart 2 shows the flowchart of sample management.

Of all AEs occurring in the department, 11 cases (45.83\%) were maternal or neonatal mortality cases, while the rest were morbidity cases.

\section{Distribution of AEs Based on Location}

Based on the location where AE occurred, 13 cases (54\%) occurred in emergency room (ER), 4 cases (17\%) in intensive care unit (ICU), 4 cases (17\%) in operating theatre (OT), and 3 cases (12\%) in the hospital ward. There was no AE that occurred in the outpatient clinic during 2015. Figure 1 illustrates the distribution of AE based on the location.

\section{Distribution of AEs Based on Contributing Factor}

The most frequent contributing factor was the lack of knowledge and skill of medical personnel $(75 \%, n=18)$, with 3 cases were due to the lack of skill, 6 cases were due to the lack of knowledge, and
Flowchart 1: Research flow diagram

Public service coordinator of Ob-gyn department, Cipto Mangunkusumo hospital (RSCM)

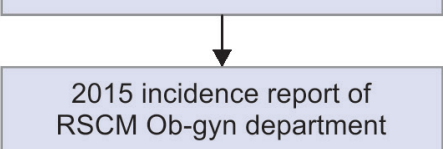
RSCM Ob-gyn department

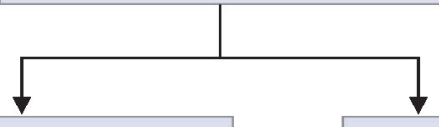

Inclusion criteria:

Incidence report which had been audited by clinical risk management team of RSCM Ob-gyn department and was classified as $\mathrm{AE}$

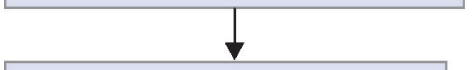

Data input to pie diagram

Data analysis

Flowchart 2: Flow diagram of sample management
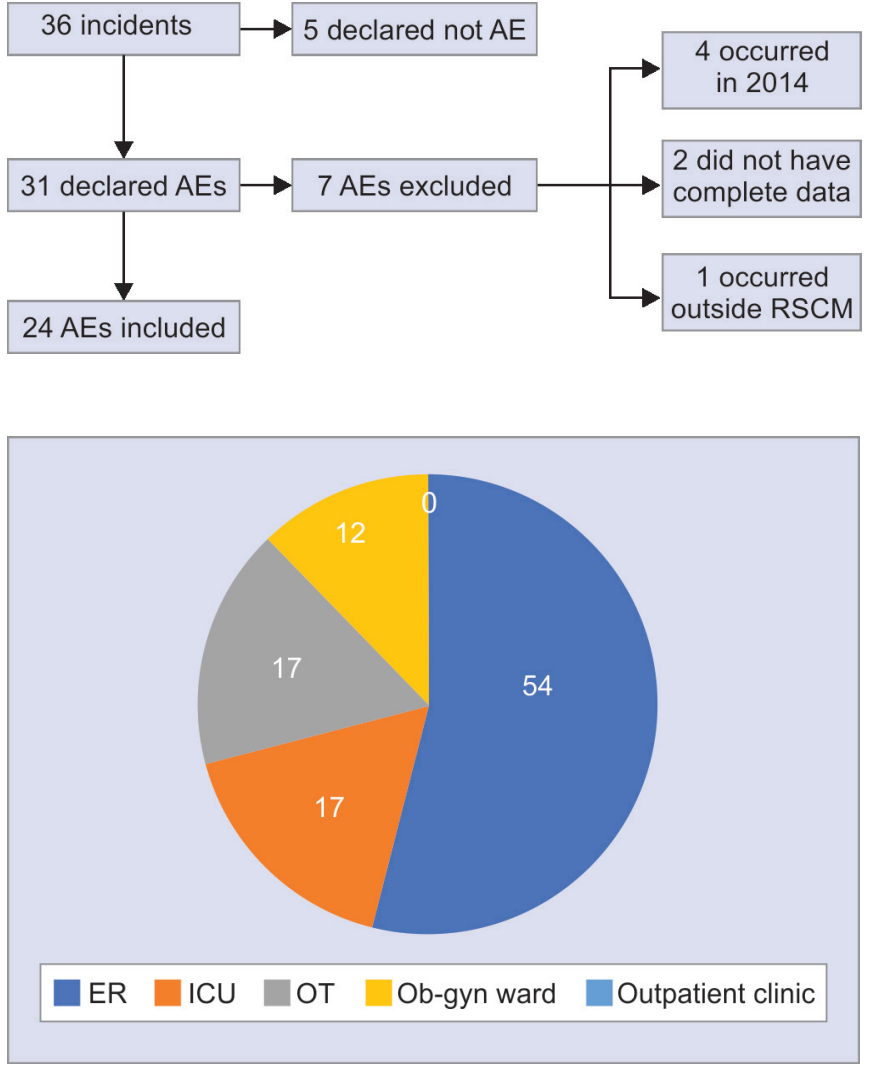

Fig. 1: Distribution of AE based on location

10 cases were due to the lack of both. Two AEs (8\%) were caused by a technical error (unavailable medical equipment) leading to delay of treatment and maternal death. Four cases (17\%) occurred due to other factors, such as unavailability of medical insurance (Fig. 2). 


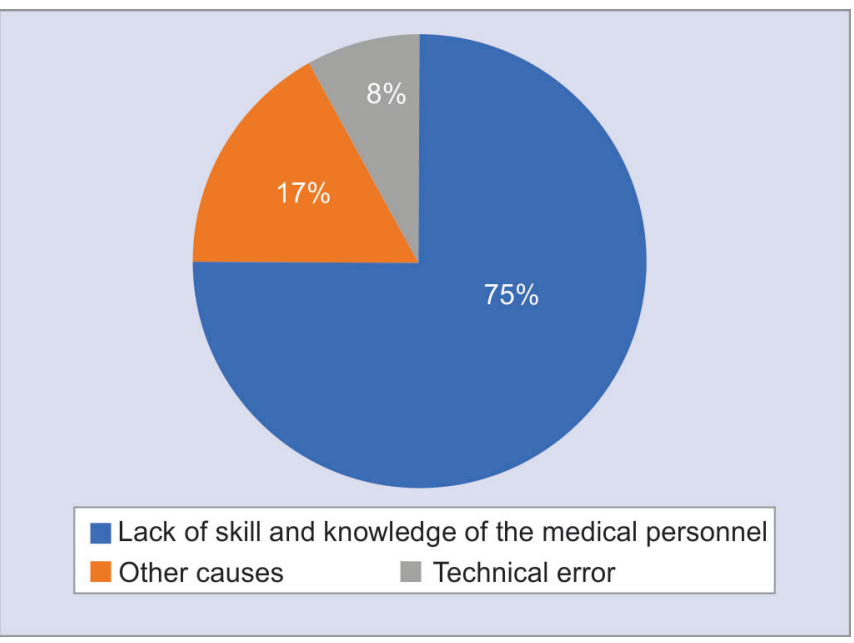

Fig. 2: Distribution of AEs based on contributing factor

\section{Distribution of AEs Based on the Failure to Prevent the Occurrence}

Based on the failure to prevent the occurrence of AEs, there were eight cases (33\%) occurred following delay in treatment, five cases (21\%) following misdiagnosis, three cases (13\%) following failure to act based on test results, six cases (25\%) following malpractice, and two cases (8\%) following failure to take precautions in order to avoid injuries. As much as 15 cases (62.5\%) of AEs caused by misdiagnosis, failure to act based on test results, and malpractice were due to the lack of skill and knowledge of the medical personnel (Fig. 3).

\section{Distribution of Additional Length of Stay Following AEs}

Additional length of stay following the occurrence of $A E$ in this study was abnormally distributed due to extreme values of 16,22 , and 34 days. The median of additional length of stay was 2 days (0-34 days; $95 \% \mathrm{CI}$ ).

\section{Discussion}

According to Regulation of Health Ministry of Indonesia (Permenkes RI) No 1691/MENKES/PER/VIII/2011, AE is an incident leading to patient injury. ${ }^{2}$ Therefore, we included only 24 cases out of 36 cases in this study.

The lack of awareness and knowledge about AEs is important factors in overlooking AE diagnosis. This is in accordance with Foster et al. in 2006 reporting discrepancy between reported AEs and actual AEs due to the lack of documentation and well-reported AEs. This also can be caused by the anxiety of the clinicians about law enforcement, creating reluctancy to report and write medical records according to the actual event.

From 24 AEs occurred in RSCM Ob-gyn Department during $2015,45.83 \%$ of which led to maternal or neonatal mortality, while the rest led to morbidity. Brennan et al. in 1991 reported that $70 \%$ of AEs in New York led to morbidity. During 2015, there were 4,253 incidents from all departments and units in RSCM, which were classified as 198 cases of AEs, 2,969 cases of near-miss, 170 cases of no harm, and 916 cases of injury potential. ${ }^{7}$ AEs in Ob-gyn Department comprised $10.81 \%$ of all AEs occurred in RSCM, which was in accordance with $2015 \mathrm{JOGC}$ report about AEs occurred in the Obstetrics department of $10 \%$.

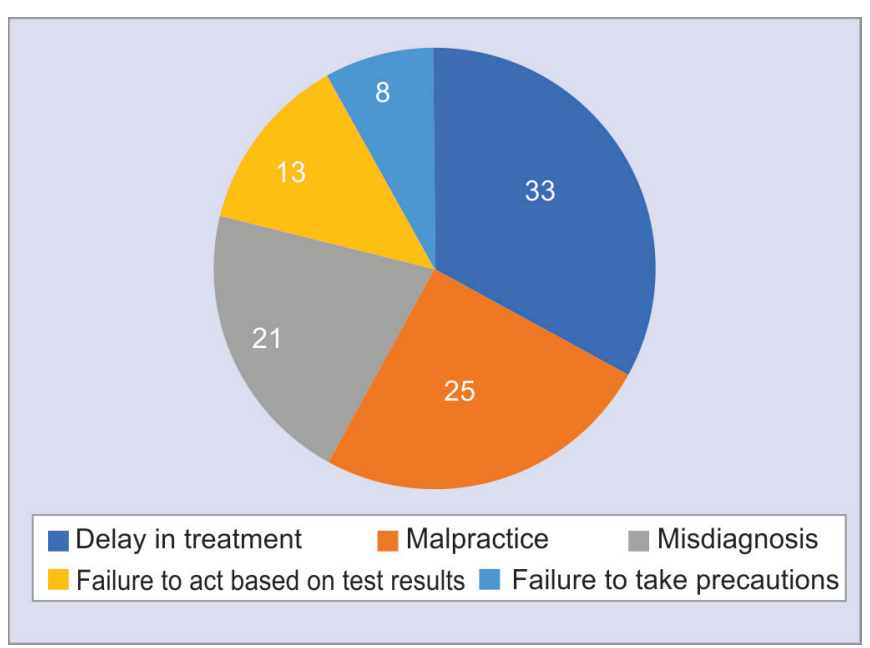

Fig. 3: Distribution of AEs based on failure to prevent the occurrence

There were four cases of maternal mortality, five cases of neonatal mortality, and two cases of both maternal and neonatal mortalities. Two cases were perimortem cesarean section followed by subtotal hysterectomy due to loss of consciousness due to gravidarum eclampsia. We identified similar problems with these mortality cases, which was a delay in treatment as a consequence of unavailable cesarean section and hysterectomy equipment in ER.

One mortality case was caused by multiple organ failure and septic shock, which occurred due to delay of diagnostic workup and treatment following financial and health insurance problems. The other maternal mortality occurred due to septic shock and disseminated intravascular coagulation following relaparotomy due to subfascial hemorrhage postcesarean section performed outside RSCM. The fifth maternal mortality was due to respiratory failure threat and lower motor neuron paraparesis due to suspected Guillain-Barre syndrome. The last maternal mortality was a case of uterine atony postcesarean section due to delayed detection of placental abruption, leading to delayed resuscitation and subtotal hysterectomy laparotomy. The last two maternal mortality cases were attributed to the lack of knowledge of the medical personnel.

There were four neonatal mortalities reported; a case of labor induction with misoprostol due to intrauterine infection, two cases of dilemmatic termination in absence of clinical guideline, the other one was a case of congenital heart anomaly with persistent bradycardia and atrioventricular septal defect. Labor induction with misoprostol was performed in three out of four cases. From all cases, it was concluded that mortality occurred as a result of a dilemma in deciding termination in absence of clinical guideline for termination, leading to delay in treatment.

\section{AEs-related Maternal Operative Morbidity}

Eight maternal morbidities following cesarean section were reported. The first case was bladder injury upon cesarean section, followed by a case of three consecutive mistakes in one patient consisting of misdiagnosis of congestive heart failure, adhesive placenta in total placenta previa, and posterior fornix laceration that led to postoperative active hemorrhage. There were five cases of hysterectomy relaparotomy due to surgical bleeding. It was concluded that those five cases occurred as a consequence of incompetent operator lacking skill and knowledge about operation technique, as the lower segment of the uterine in four 
cases were found to be inadequately sutured. The last case was total hysterectomy following cesarean section on a patient with thrombocytopenia, in which the lack of knowledge and skill of the operator hindered adequate anticipation of blood loss.

\section{AEs-related Nonoperative Morbidity}

There were five cases of nonoperative morbidity during the research period. The first case was morbidity following delayed identification and management of patient with recurrent lung edema postcesarean section, which occurred due to inappropriate patient transfer back to ER. The second case was a misdiagnosis of the adhesive placenta following curettage on the posterior implanted placenta. The third was a misdiagnosis of rupture of ectopic pregnancy leading to grade 3 hypovolemic shock. The fourth was a failure to identify complete placental component in preterm delivery. The last case was delayed treatment for 34 days due to misdiagnosis of abdominal tuberculosis, which was previously thought as endometriosis and adenomyosis.

\section{Distribution of AEs}

This study found that $54 \%$ of AEs occurred in ER, 17\% in ICU, 12\% in Ob-gyn ward, and $17 \%$ in OT. Friedman et al. reported that $60 \%$ of AEs in ER was actually preventable. ${ }^{8}$ There were studies supporting these findings as well as contradictory. The proportion of AEs occurring in the hospital ward was in accordance with the range reported in Canada of $2.7-12.5 \% .{ }^{9}$ This study found that the greatest proportion of AEs occurred in ER and ICU, while Murff reported outpatient clinic (up to 35\%) and hospital ward (19\%) were the places AEs mostly occur. ${ }^{10}$

This study found that the most frequent factor leading to AEs was the lack of skill and knowledge of the medical personnel (75\%), while delay in treatment being the most frequent the failure to prevent the occurrence (33\%). As much as $62.5 \%$ of AEs occurred following misdiagnosis, inappropriate medical treatment, and medical failure were composite elements of the lack of skill and knowledge of the medical personnel. This prominent factor found in our study corresponded to Geurden et al. and Law et al., reporting that the lack of knowledge and skill of the medical personnel was the leading contributing factor of AEs. ${ }^{11,12}$ However, this finding was contradictory with Lyons et al. who reported missing of the information and miscommunication as the leading cause of AEs. ${ }^{13}$ This contrast might be due to different knowledge and skill level between hospitals as well as the sampling methods. We performed a descriptive sampling method without interview, as opposed to Lyon's method of a closed counseling session.

It is worth noting that RSCM serves as a teaching hospital in which medical personnel consisted of residents with different stages of education and competence. Bari et al. reported that medical error was attributed to intrinsic and extrinsic factors, that consisted of physician fatigue, lack of experience, lack of knowledge, and unawareness towards warning signs. ${ }^{14}$

The data of the additional length of stay following AEs were abnormally distributed owing to extreme values of 16,22 , and 34 days, with median value of 2 days $(0-34$ days; $95 \% \mathrm{Cl})$. This finding was shorter compared to Weingart et al. who reported 4 days ( $0-36$ days). ${ }^{15}$ There might be a bias in a shorter length of stay related to mortality cases since we did not separate sentinel AEs.

We encountered several limitations during the study, among others are limited sample size as it was a pilot study and the use of secondary data that had its bias nature, therefore, could reduce the accuracy of AEs prevalence.

\section{Conclusion}

This was a pilot study about AEs in RSCM. AEs mostly occurred in ER (54\%) with lack of knowledge and skill of the medical personnel as the greatest contributing factor (75\%), delayed treatment being the most frequent failure to prevent the occurrence (33\%), and led to additional length of stay with median value of 2 days. Further studies of the following year with greater sample size, survey-based and closed questionnaire are recommended to obtain deeper analysis and accuracy about the occurrence of AEs, particularly about the intrinsic factor leading to inadequate human resources.

\section{Declarations}

\section{Ethics Approval and Consent to Participate}

This study was approved by the Ethic Committee of Faculty of Medicine of Universitas Indonesia (0717/UN2.F1/ETIK/2018).

\section{Consent for Publication}

All authors have consented for the publication of this article.

\section{Availability of Data and Material}

Research data are available upon request to the corresponding author.

\section{ACKNOWLEDgMENTS}

We thank Omo Abdul Madjid, Fitriyadi Kusuma, and M. Ilhamy S for the valuable ideas, suggestions, and feedback during the research.

\section{References}

1. Richardson WC, Bisgard JC, Bristow LR, et al. To err is human: building a safer health system. United States: Institute of Medicine; 1999.

2. PERSI. Buku Panduan Nasional Keselamatan Pasien Rumah Sakit (Patient Safety). Jakarta: Departemen Kesehatan Republik Indonesia; 2006.

3. Mendes W, Pavao AL, Martins M, et al. The feature of preventable adverse events in hospitals in the State of Rio de Janeiro, Brazil. Rev Assoc Med Bras 2013;59(5):421-428. DOI: 10.1016/ j.ramb.2013.03.002.

4. Murray-Davis B, McDonald H, Cross-Sudworth F, et al. Learning from adverse events in obstetrics: is a standardized computer tool an effective strategy for root cause analysis? J Obstet Gynaecol Can 2015;37(8):728-735. DOI: 10.1016/S1701-2163(15)30178-X.

5. Peraturan Menteri Kesehatan Republik Indonesia Keselamatan Pasien Rumah Sakit, Nomor 1691/MENKES/PER/VIII/2011. Sect. III; 2011.

6. Yully HM. Analisis Determinan Kejadian Nyaris Cedera dan Kejadian Tidak Diharapkan di Unit Perawatan Rumah Sakit Pondok Indah Jakarta. Depok, Jawa Barat: Universitas Indonesia; 2011.

7. Sabrina D. Kajian Operasional Laporan Insiden RSCM Tahun 2015. RSUPN dr Cipto Mangunkusumo: Komite Mutu, Keselamatan Pasien, dan Kinerja; 2019.

8. Friedman SM, Moore S, Provan D, et al. Errors, near misses and adverse events in the emergency department: what can patients tell us? CJEM 2008;10(5):421-427. DOI: 10.1017/s1481803500010484.

9. Forster AJ, Fung I, Caughey $S$, et al. Adverse events detected by clinical surveillance on an obstetric service. Obstet Gynecol 2006;108(5):1073-1083. DOI: 10.1097/01.AOG.0000242565.28432.7c.

10. Murff HJ, Patel VL, Hripcsak G, et al. Detecting adverse events for patient safety research: a review of current methodologies. J Biomed Inform 2003;36(1-2):131-143. DOI: 10.1016/j.jbi.2003.08.003.

11. Geurden B, Wouters C, Franck E, et al. Does documentation in nursing records of nutritional screening on admission to hospital reflect the use of evidence-based practice guidelines for malnutrition? Int J Nurs Knowledge 2014;25(1):43-48. DOI: 10.1111/2047-3095.12011. 
12. Law L, Akroyd K, Burke L. Improving nurse documentation and record keeping in stoma care. Br J Nurs 2010;19(21):1328-1332. DOI: 10.12968/ bjon.2010.19.21.80002.

13. Lyons PG, Arora VM, Farnan JM. Adverse events and near-misses relating to intensive care unit-ward transfer: a qualitative analysis of resident perceptions. Ann Am Thorac Soc 2016;13(4):570-572. DOI: 10.1513/AnnalsATS.201512-789LE.
14. Bari A, Khan RA, Rathore AW. Medical errors; causes, consequences, emotional response, and resulting behavioral change. Pak J Med Sci 2016;32(3):523-528. DOI: 10.12669/pjms.323.9701.

15. Weingart SN, Pagovich O, Sands DZ, et al. What can hospitalized patients tell us about adverse events? Learning from patient-reported incidents. J Gen Intern Med 2005;20(9):830-836. DOI: 10.1111/ j.1525-1497.2005.0180.x 